\title{
Effectiveness Of An Instructional Brochure On Relieving
}

\section{Postpartum Blues}

\author{
By \\ ${ }^{1}$ Ahlam Mohamed Ibrahem Gouda ${ }^{2}$, Tyseer Mohamed Fathy, ${ }^{3}$ Laila \\ Elboghdady, ${ }^{4}$ Amina Mohamed Rashad El-Nemer'
}
1,2,4 Maternity and Gynecology of Nursing, Faculty of Nursing, Mansoura University 3 Obstetrics \& Gynecology, Faculty of Medicine, Mansoura University, Email: ahlam_goda2000@yahoo.com

\begin{abstract}
Background: Postpartum blues is a transitional depressive state that viewed as a highly prevalent mental health problem.Setting of the study: the study was conducted in Obstetrics and Gynecology department at Mansoura University Hospitals. Aim of this study: is to assess the effectiveness of an instructional Brochure on relieving postpartum blues. Research Hypothesis: The intervention group who will receive informational instructions brochure about postnatal blues within the first day of giving birth will experience lesser blues at end of 1st week postpartum than the control group. Study Design: Intervention study design carried out between of January 2013 to July 2013. Methods: Intervention study design was conducted in Obstetrics and Gynecology department at Mansoura University Hospitals on 184 postnatal women. Women divided into two groups: control group; received routine discharge instructions and intervention group received information on postpartum blues, on top of routine discharge instructions. Socio-demographic data questionnaire and Arabic version of Beck Depression Inventory Questionnaire (BDI) are used for data collections. Participants filled in both tools on first day of birth and BDI alone at end of 1st and 2nd week postpartum. Results: The study findings revealed that frequency of blues at end of 1st week postpartum is lower in the intervention group than the control group (20.7\% versus $69.5 \%)$. Conclusion: Instruction information about postnatal blues within the first day of giving birth is an effective method on relieving postpartum blues. Recommendations: The educational brochure was recommended to be distributed and implemented in all maternity health services and $\mathrm{MCH}$ center in Mansoura Governorate.
\end{abstract}

Key word: Instructional information, postpartum blues, postpartum psychological disorders and Beck Depression Inventory Questionnaire

\section{Introduction:}

Postpartum period or puerperium is the period of time following delivery of the child during which the body tissues, especially the reproductive system reverts to the pre-pregnant state, 
Ahlam Mohamed Ibrahem Gouda..at.el.

both anatomically and physiologically ${ }^{(1,2)}$.

According to Bobak and Jensen (2009), the word puerperium is from the Latin language, where puer, meaning "child" and perium, meaning, "to bring forth". (3) The puerperium or postpartum period begins immediately after childbirth and lasts for approximately six weeks, or until the body has completed its adjustment to a state of non-pregnancy. Healthcare professionals believe that the period after delivery is a time for psychological restoration and a time when parents develop a relationship with their infant. ${ }^{(4)}$

Postpartum psychological disorders are serious conditions experienced by women soon after giving birth. Many types of affective disorders occur in the postpartum period, and based on their severity psychological disorders classified as postpartum blues, postpartum depression and postpartum psychosis. (5) Postpartum blues is a transitional depressive state that viewed as a highly prevalent mental health problem. This phenomenon characterized by depressed mood, fatigue, tearfulness and mild insomnia, and affects $50-80 \%$ of new mothers. It begins 3-4 days after delivery, peak between 5 th and 7 th postpartum day and resolve by the twelfth postpartum day. ${ }^{(6,7)}$
The blues may have several causes, some biological and some emotional. Biological causes arise from hormonal fluctuation as when a baby is born, there are sudden changes in the mother's hormone levels. Pregnancy hormones drop rapidly while others increase like those which responsible for milk production, these rapid changes may act to trigger the blues. Emotional causes may be due to lack of antenatal care and preparing of pregnant woman for the extreme tiredness, which often follows a birth. (8) Several studies have investigated the effect of support on women's psychological health during the postpartum period. Elliottet al. (1988) found that an educational programme covering postnatal depression, common realities of life with a newborn baby, and ways of preparing for the new job of parenting in pregnancy were successful in reducing the prevalence of postnatal depression for vulnerable parent groups (poor marital relationship, personal psychiatric history, lacking a confidante, and high level of anxiety) and especially for firsttime mothers. ${ }^{(9)}$

Holden et al. (1989) conduct an experimental study which revealed that postnatal depression is responsive to nondirective counseling and to therapeutic listening and support by health visitors. Parents complained about 
'not having been warned about the possibility of low mood' and felt that this would better enable them to cope with the problem. ${ }^{(10)}$

The mother diagnosed with postpartum blues does not require any medical intervention, but during this period, she required more information regard postpartum period through health education and counseling. (11,12) This enforcing the current study to assess the effectiveness of an instructional Brochure on relieving postpartum blues.

Nurse has an important role to minimize postpartum blues, she should enhance the quality of maternal adjustment and promoting effective coping strategies for promoting feelings of wellbeing, comfort and satisfaction, information, emotional support, and assistance in providing or obtaining care are needed. Helping family members by identifying community resources and making referral to social services postpartum follow up and visits from a psychiatric health nurse are especially important. ${ }^{(13)}$

The nurse should assess factors predisposing to postpartum blues. In providing routine care the nurse should assess the pregnant woman for: Marital status, socioeconomic status, self-esteem and personality building, prenatal anxiety and emotional liability, history of previous psychological problems, unplanned/unwanted pregnancy, the availability of social support, marital satisfaction, life stressors and management strategies, sociodemographic characteristics and assessment for support systems ${ }^{(14)}$

Adequate assessment of the mother's psychological adjustment is an integral part of postpartum period evaluation, this assessment focuses on the mother's general attitude, feeling of competence, level of confidence, available support systems, and care giving skills, it also evaluates her fatigue level, sense of satisfaction, and ability to accomplish her development tasks and assessment of the teaching needs based on interview \& observation ${ }^{(15)}$

After assessing the women for predisposing factors. The nurse must review it carefully for formulating nursing diagnosis and implement a care plan. Nurses should help parent appreciate the life style changes and role attainment for parenthood, offering realistic information and anticipatory guidance may help prevent postpartum blues, social support, teaching guides are available for nurses to help postpartum women explore their needs for postpartum support. ${ }^{(16)}$

\section{Research Hypothesis}

The intervention group who will receive informational instructions brochure about postnatal blues within the first day of giving birth 
was experienced lesser blues at end of 1 st week postpartum than the control group..

\section{Significance of the problem}

Postpartum period consider stressful event for most rural areas mother due to lack of information during this period which may lead to biological and psychological disorders, no pervious study was conduct at Maternity and Gynecological Nursing Department, Faculty of Nursing, Mansoura University.

Research implemented an instructional Brochure about postnatal period to reduce maternal-neonatal biological and psychological disorders.

\section{Subjects and Method}

\section{Setting:}

The study was conduct in Postpartum Inpatient Ward and Labor and Delivery Unit of Obstetrics and Gynecology department at Mansoura University Hospitals.

\section{Study Design}

Intervention study design carried out between of January 2013 to July 2013.

Subjects: according to hospital statistics 2012-2013, subjects was selected during 1 st day postpartum and was divided into two groups, an intervention group who received an instructional brochure, the second group was control group who receive routine care. Contributed to this study women post-vaginal delivery or post cesarean section with the following inclusion criteria:

1. Aged 20 to 35 years.

2. Free from obstetric or psychiatric problems on current pregnancy.

3. Had single full term, live baby.

4. Accepted to participate in study.

Sample size: Sample size for the current study was calculated using the following formula: $\mathrm{N}=$ $\mathrm{Z} 2(\mathrm{Pq}) / \mathrm{d} 2$. Where $\mathrm{N}$ is the required sample size and $\mathrm{Z}$ equal 1.96 and $\mathrm{P}$ (proportion affected) equal $40 \%$ and $\mathrm{q}$ (proportion not affected) equal $60 \%(1-p)$ and $d$ (degree of probability) equal 0.05 , total subjects were 184 postnatal women.

Purposive sampling technique employed to recruit participants based on the predetermined inclusion and exclusion criteria. A randomly selected 210 postnatal women interviewed. After baseline evaluation the eligible women were randomly allocated by means of block randomization (block size of 4) into two matched groups $(n=92$ per each group).

- Control group: received routine discharge instructions.

- Intervention group: received information on postpartum blues, on top of routine discharge instructions. 
Effectiveness of an Instructional Brochure on Relieving Postpartum Blues

\section{Ethical considerations}

- Ethical approval obtained from the research committee of the faculty of nursing.

- Official Permissions obtained from the head of Obstetrics and Gynecology department and the Director of Mansoura University Hospital.

- The objective of the study explained to the studied population and their oral consents obtained.

- All ethical issues considered in dealing with obtained information.

- Women had the right to withdraw from the study at any time, and their data were confidential.

- Information including Brochure didn't harm psychological sexual aspects of women.

- After analysis of data collection was burned to promote mother confidently.

After collecting the required data (at end of 2nd week postpartum), the control group were given basic information about postpartum blues for ethical issue.

Tools: To achieve the aim of this study, two tools used for data collection.

Tool I: a Structured Interview Questionnaire

It designed to assess the sociodemographic characteristics of the participants (e.g., name, telephone number, age, residence, educational level, occupation, family income, marital status and duration of marriage). obstetrical history, details of current pregnancy.

Tool II: "Arabic version of Beck Depression

Inventory Questionnaire"

It consists of 21 items to assess the intensity of depression in clinical and normal population on a selfreport scale. It assesses physical and psychological symptoms of depression such as mood, pessimism, sense of failure, selfdissatisfaction, guilt, punishment, self-dislike, self-accusation, suicidal ideas, crying, irritability, social withdrawal.

On the BDI, respondent provide severity ratings for each of 21 depressive symptoms during the past week including today. On a 4point Likert scale, ranging from zero (e.g., I do not feel disappointed in myself) to three (e.g., I hate myself). The highest score for each of the twenty-one questions is three, the highest possible score for the whole test would be sixty-three if the patient marked number 3 on all the questions, and the lowest possible score for the test would be zero if the woman marked zero on each question. Twenty-five years of research has yielded strong support for validity and reliability of the BDI. ${ }^{(11)}$ This study was conducted using Arabic version of BDI scale that was translated by Psychiatric 
Department of Faculty of Nursing at Ain shams University and based on BDI score 10-15 as a diagnostic criterion for maternity blues. ${ }^{(12)}$

Tools send to 3 juries according their comments modification was done

The relationship between total score and level of depression. (17)

\begin{tabular}{|l|l}
\hline $\begin{array}{c}\text { Total } \\
\text { Score }\end{array}$ & \multicolumn{1}{c}{ Level of Depression } \\
\hline $0-9$ & $\begin{array}{l}\text { These ups and downs are } \\
\text { considered normal }\end{array}$ \\
\hline $10-15$ & $\begin{array}{l}\text { Mild mood disturbance } \\
\text { (blues) }\end{array}$ \\
\hline $16-23$ & Moderate depression \\
\hline $24-36$ & Severe depression \\
\hline Over 36 & Extreme depression \\
\hline
\end{tabular}

\section{Administrative Design}

After clarifying the aim of the work, approval to undertake the study gained from the directors of the hospital.

\section{Operational Design}

This design includes preparatory phase description, pilot study, and fieldwork.

\section{Preparatory Phase}

After extensive literature review, tools of data collection were prepared based on review of related literatures.

\section{Pilot Study}

A pilot study conducted on $10 \%$ of the predetermined sample size. BDI questionnaire validated before the participants were included. Validation tested to confirm that the questions consistently delivered to women and that they carry the intended meaning they were designed for. It also helped to estimate the time needed to complete the questionnaire. The results of the pilot indicated that the statements of the questionnaire were clear and relevant, and few words and items modified. The pilot sample excluded from the study based on the modifications that done.

\section{Field Work}

- The researcher visited the previous mentioned settings from 9 am to $2 \mathrm{pm}$ for three days per week.

- Firstly the researcher interviewed each mother in separate place, introduced herself to each participant, a full explanation about the aim, and scope of the study was given to obtain women's acceptance and oral consent. Complete instructions regarding answering the BDI questionnaire sheet were given.

- The intervention group was given specific information during the hospitalization period about postpartum blues in the form of oral discussion on one session (30-40 minutes) and a printed book of 16 paper that entails information about definition, causes, incidence, high risk groups, symptoms, effects of postpartum blues on mother and child health, and 
whom she can ask help if developed postpartum blues. Moreover, it includes general instructions to woman, her husband and family of how to prevent postpartum blues. While routine discharge instructions given to the control group subjects.

- During the hospitalization period each participant filled in tool I and tool II at the first day after delivery through an individual interview with the researcher (took 20-25 minutes per each woman). Eligible participants received two copies of the BDI questionnaire to fill in at the end of $1^{\text {st }}$ and $2^{\text {nd }}$ week postpartum and their answers were provided to the researcher by telephone conversations. The BDI data on the first day served as baseline data for further comparison.

\section{Statistical Design}

All statistical analyses were performed using SPSS for windows version 17.0 (SPSS, Chicago, IL). Continuous data were expressed as mean \pm standard deviation (SD). Data were checked for normality and equality of distribution, prior to any analysis being performed. Skewed continuous variables were logarithmically transformed to attain a normal distribution. For variables that would not attain a normal distribution by logarithmic transformation, nonparametric tests would be used .

The correlation between the BDI and continuous variables were assessed by Pearson correlation coefficient test. The comparison of the BDI scores between participants with versus without clinical finding and the comparison of the continuous variables between the intervention group and the control group were assessed using independent student's $t$ test. Comparison of categorical data was assessed using the chi square text. p-values $<0.05$ were considered to be of statistical significance.

\section{Results:}

Table1. Shows sociodemographic characteristics of the control and intervention groups. It is obvious that, there were no statistical significant differences regarding the sociodemographic characteristics among the both groups. The mean age of the control group was slightly lower than the intervention group

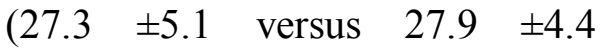
respectively). Women from rural origin were more than those from urban origin $(63 \%$ and $56.5 \%)$ respectively of the control and intervention groups. Secondary/university was the highly distributed educational level. It was less in the control group than in the intervention group $(50 \% \quad$ and $58.7 \%)$ 
Ahlam Mohamed Ibrahem Gouda..at.el.

respectively. Concerning occupation, it is clear that house wives were more than worker women in the control and intervention groups $(69.6 \%$ versus $72.8 \%$ respectively). Nearly the same percentage $(50 \%$ and $51.1 \%)$ among the control and intervention groups respectively had only enough family income. Nearly the same percentages $(95.7 \%$ and $96.7 \%)$ in the control and intervention groups respectively were married. With a mean duration of marriage of $3.8 \pm 2$ versus $4.8 \pm 2.3$ in the control and intervention groups respectively.

Table 2. Shows the frequency of blues among the control and intervention groups at end of $1^{\text {st }}$ week and $2^{\text {nd }}$ week postpartum. It reveals that $69.5 \%$ of the control group diagnosed with blues at end of 1 st week postpartum compared to $20.7 \%$ only in the control group at the same point of assessment. Both percentages reduced at the end of 2nd week postpartum being $(22.8 \%$ versus $5.4 \%)$ respectively in the control and intervention groups. Difference observed was highly significant $(\mathrm{p}<0.001)$.

Figure 1 shows the comparison of BDI total score at baseline, 1 week and 2 weeks postpartum

between the control and intervention groups. The BDI total score decreased in the intervention group 1 week postpartum than BDI total score at baseline $\quad(10.8 \pm 2.3, \quad 8.6 \pm 2.7$ respectively) compared to (12 $\pm 2.5,8.4 \pm 2.5$ respectively) in the control group. Differences observed are not statistically significant at day one postpartum $\mathrm{p}=0.6582$ and statistically significant at $1^{\text {st }}$ and $2^{\text {nd }}$ week postpartum ( $p=0.002$ and 0.0363$)$.

Figure 2 shows correlation between 1st week BDI total score and the age of the studied sample. It is clear that BDI total score was significantly correlated (positive correlation) with maternal age of the studied sample $(\mathrm{r}=0.171$ and $\mathrm{p}=0.020$ ).

Table 3 shows the correlation between 1st week BDI total score and obstetric history of the studied sample. The 1 st week BDI total score was found to be significantly correlated to the number of living children $(\mathrm{r}=0.151$ and $\mathrm{p}=0.040)$ whereas BDI total score did not show significant correlation with gravidity, parity, abortion or gestational age $(\mathrm{p}>0.05)$. 
Table 1. Socio-demographic characteristics of the control and intervention groups

\begin{tabular}{|c|c|c|c|c|}
\hline $\begin{array}{l}\text { Socio-demographic } \\
\text { characteristics }\end{array}$ & $\begin{array}{l}\text { Control group } \\
(\mathbf{n}=92)\end{array}$ & $\begin{array}{c}\text { Intervention } \\
\text { group } \\
(\mathbf{n}=\mathbf{9 2})\end{array}$ & $\mathbf{X} 2$ & $\mathbf{P}$ \\
\hline Age (years) Mean \pm SD & $27.3 \pm 5.1$ & $27.9 \pm 4.4$ & $0.864 *$ & 0.389 \\
\hline \multicolumn{5}{|l|}{ Residence } \\
\hline Rural & $58(63 \%)$ & $52(56.5 \%)$ & 0.452 & 0.226 \\
\hline Urban & $34(37 \%)$ & $40(34.5 \%)$ & & \\
\hline \multicolumn{5}{|l|}{ Educational level } \\
\hline Illiterate & $17(18.5 \%)$ & $9(9.8 \%)$ & 3.102 & 0.212 \\
\hline Primary/preparatory & $29(31.5 \%)$ & $29(31.5 \%)$ & & \\
\hline Secondary/university & $46(50 \%)$ & $54(58.7 \%)$ & & \\
\hline \multicolumn{5}{|l|}{ Occupation } \\
\hline Housewife & $64(69.6 \%)$ & $67(72.8 \%)$ & 0.239 & 0.625 \\
\hline Working & $28(30.4 \%)$ & $25(27.2 \%)$ & & \\
\hline \multicolumn{5}{|l|}{ Family income } \\
\hline Permanent debt & $2(2.2 \%)$ & $2(2.2 \%)$ & 0.045 & 0.997 \\
\hline Not enough & $29(31.5 \%)$ & $29(31.5 \%)$ & & \\
\hline Only enough & $46(50 \%)$ & $47(51.1 \%)$ & & \\
\hline More than enough & $15(16.3 \%)$ & $14(15.2 \%)$ & & \\
\hline \multicolumn{5}{|l|}{ Marital status } \\
\hline Married & $88(95.7 \%)$ & $89(96.7 \%)$ & 0.339 & 0.844 \\
\hline Divorced & $2(2.2 \%)$ & $2(2.2 \%)$ & & \\
\hline Widowed & $2(2.2 \%)$ & $1(1.1 \%)$ & & \\
\hline Duration of marriage & $3.8 \pm 2$ & $4.8 \pm 2.3$ & $0.2097^{*}$ & 1.259 \\
\hline
\end{tabular}

* Student's t test

Table 2. Frequency of blues among the control and intervention groups at end of 1st week and 2 nd week postpartum

\begin{tabular}{|l|c|c|c|c|}
\hline \multicolumn{1}{|c|}{ BDI Total score at } & $\begin{array}{c}\text { Control group } \\
(\mathbf{n = 9 2})\end{array}$ & $\begin{array}{c}\text { Intervention group } \\
(\mathbf{n = 9 2})\end{array}$ & $\mathbf{X 2}$ & $\mathbf{P}$ \\
\hline 1 week postpartum & $64(69.5 \%)$ & $19(20.7 \%)$ & 44.4 & $<0.001$ \\
\hline 2 weeks postpartum & $21(22.8 \%)$ & $5(5.4 \%)$ & 11.5 & $<0.001$ \\
\hline
\end{tabular}


Ahlam Mohamed Ibrahem Gouda..at.el.

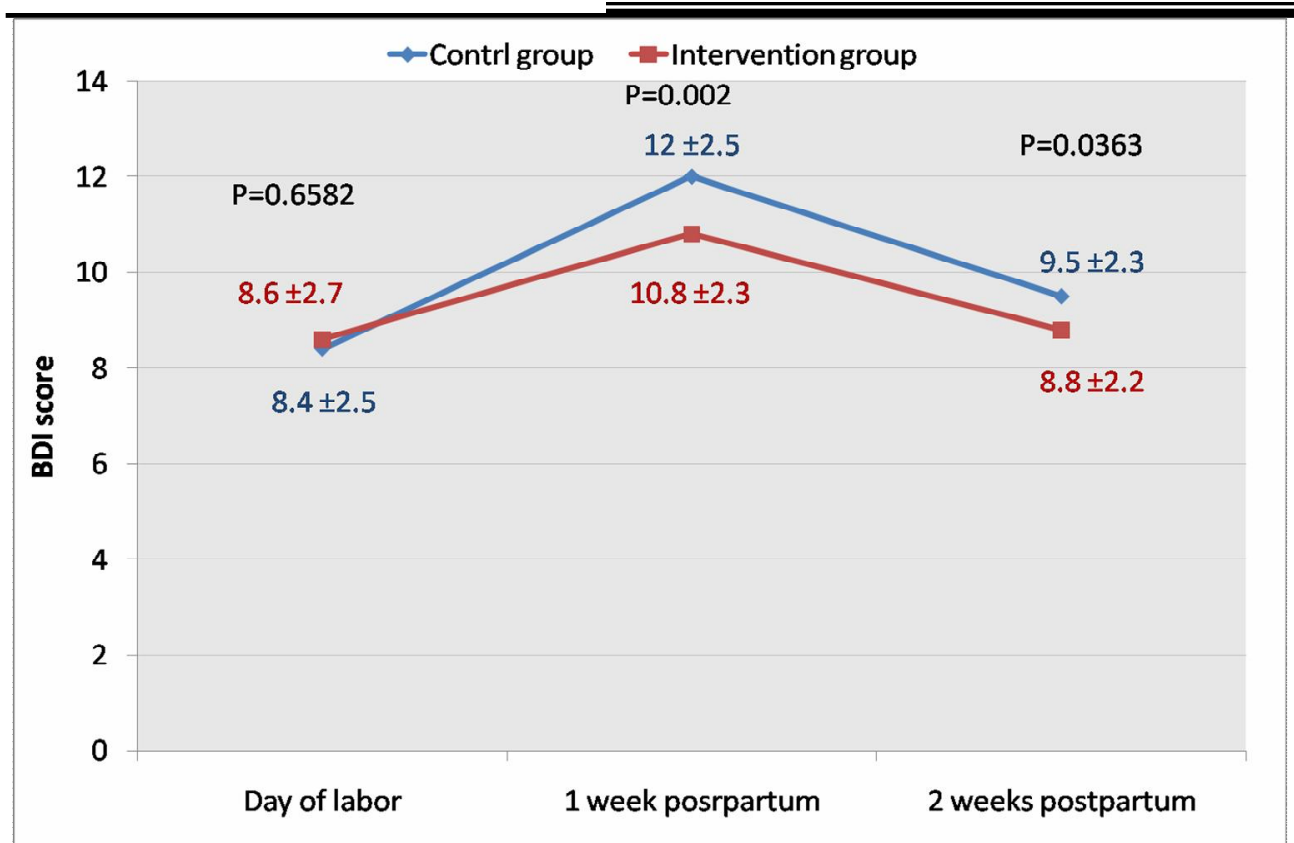

Figure 1. Comparison of BDI total scores between the control and intervention groups at 1 st day, and at the end of 1 st and 2 nd week postpartum

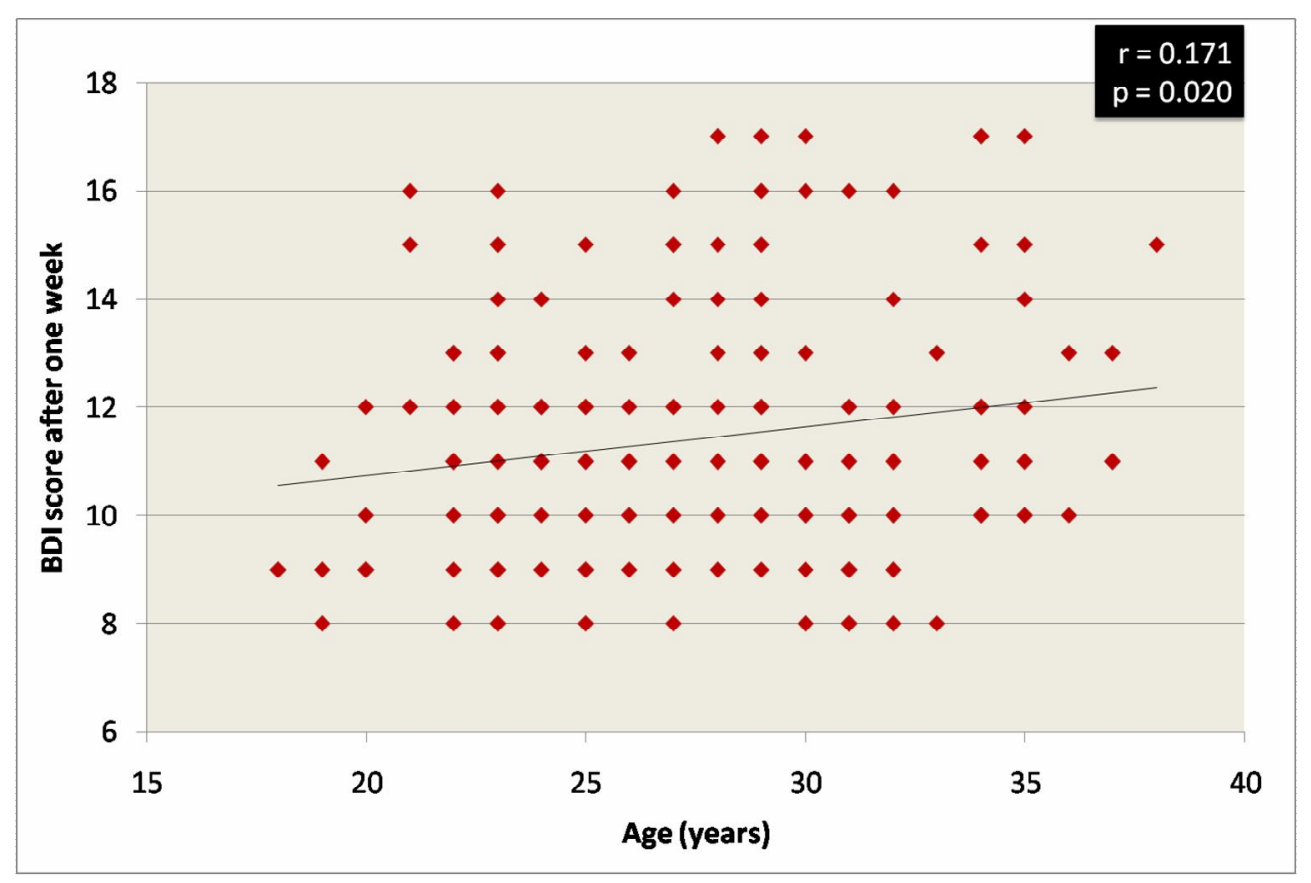

Figure 2. Correlation between $1^{\text {st }}$ week BDI total score and the age of the studied sample 
Effectiveness of an Instructional Brochure on Relieving Postpartum Blues

Table 3. Correlation between $1^{\text {st }}$ week BDI total score and obstetric history of the studied sample

\begin{tabular}{|l|c|c|}
\hline \multicolumn{1}{|c|}{ Obstetric history } & r & P \\
\hline Gravidity & 0.087 & 0.240 \\
\hline Parity & 0.117 & 0.114 \\
\hline Abortion & 0.050 & 0.503 \\
\hline Number of living children & 0.151 & 0.040 \\
\hline Gestational age (weeks) & 0.116 & 0.118 \\
\hline
\end{tabular}

\section{Discussion:}

Postpartum period is a happy time. However, it considered a stressful period due to lack of information and knowledge regarding this period. This may lead to psychological disorders. ${ }^{(18,19)}$

The study findings revealed that the intervention group; who received informational instructions about postnatal blues within the first day of giving birth had lower percentage of blues at end of $1^{\text {st }}$ week postpartum than the control group $(20.7 \%$ versus $69.5 \%$ respectively). Such findings supported the study hypothesis that, the intervention group who receive informational instructions about postnatal blues within the first day of giving birth will experience lesser blues at end of $1^{\text {st }}$ week postpartum than the control group.

In this study, although BDI total score did not show significant differences among control and intervention groups at baseline, however these scores decreased in the intervention group at the end of the $1^{\text {st }}$ week postpartum compared to the control group, and return nearly to the base line at end of $2^{\text {nd }}$ week postpartum.

In agreement to our findings, Chen et al. (2000) who conducted a randomized controlled study to evaluate the effects of educational information on women suffering postpartum depression. Sixty postpartum women with a Beck Depression Inventory score of 10 or greater were randomly assigned to intervention and control groups. The results showed that a support group results in psychological benefit for postnatal distressed women ${ }^{(20)}$

Similarly, Navaie-Waliseret al. (2000) found that high-risk mothers provided with more intensive support by home visitors were less depressed, and the frequency of home visits is an important component in improving women's psychological health ${ }^{(21)}$ And, Nahas et al. (1999) found that insufficient knowledge was one of the themes in women's experience of postpartum 
Ahlam Mohamed Ibrahem Gouda..at.el.

depression $^{(22)}$ For many depressed mothers the best intervention may be to reassure them that their experience is not unique and provide them enough information about postnatal depression. ${ }^{(23)}$

Study findings may be explained by; providing information may increase clients' understanding and have a positive impact on their functioning and ability to deal with stress. Also, understanding and explanation given to women in the postnatal period contributes towards psychological well-being.

There are three limitations in this study. Firstly, data collection was somewhat difficult due to the necessity of assessing women for postpartum blues within the1st day postpartum, at end of first and at end of second week postpartum, which led to high dropout rate (26 mothers) that took additional time for replacing this number to complete the predetermined sample size. Secondly, the Beck Depression Inventory scale that used in the present study is not specifically to screen women for depression in the postpartum period, while the BDI used with the general adult population. Lastly, baseline assessment done in the hospital's rooms with a patient capacity of 4-6 women per room, lack of adequate privacy during individual interviews and women's reluctance to openly discuss their feelings may result in under- or over reporting bias.

\section{Conclusion:}

Educational information about postnatal blues within the first day of giving birth is an effective method on reducing postpartum blues at end of $1^{\text {st }}$ week postpartum.

\section{Recommendations:}

In the light of the study findings, the following are recommended

The educational brochure was recommended to be distributed and implemented in all maternity health services and $\mathrm{MCH}$ center in Mansoura Governorate.

The study suggest postpartum supportive group to promote mother - neonatal health and reducing postpartum blues in postpartum period.

The instruction brochure about reducing postpartum blues is suggested to caring of mothers during postpartum period.

Postpartum brochure must be giving to each mother as hospital education before discharge .

\section{References}

1. Bick D, MacArthur C, \&Winter H (2010): Postnatal Care Evidence and Guidelines for Management. 2ed London: J.B, Elsevler Co., pp. 139.

2. Carels, A., (2012): What to expect after childbirth, http//: www. Feelgood Health. Last Retrived at 18/3/2013. 
3. Bobak, I., and Jensen, M., (2009): Normal Postpartum and Normal Childbirth, ( 6th ed.). St. Louis: Mosby.

4. Sherwin, L., Scoloveno, M., \& Weingarten,C. ,(2012): Nursing Care of the Childbearing Family, (3rd ed.). Norwalk: Appleton \& Lange

5. Douglas, C.J. (2010): Teaching supported therapy to psychiatric residents. American Journal of Psychiatry; 156(4): 445-452.

6. Gabeyma, S., and Harlow, B., (2009): Postpartum mood disorders: A review of clinical and epidemiological factors. Psychosom Obst Gynecol, 24:pp.257-266.

7. Ruchala, P., (2010): Teaching new mothers: Priorities of nurses and postpartum women. JOGNN: Journal of Obstetric, Gynecologic, and Neonatal Nursing, 29,pp. 265-273.

8. Braverman, J. \& Roux, J. F. (2008): Screening for the patient at risk for postpartum depression. Obstetrics and Gynecology, 52, 731-736.

9. Kneeth, S. \& Kendler, M. (2008): Sex differences in the relationship between social support and risk for depression: A longitudinal study of opposite sex twin pairs. Mental health and psychiatry news. American Journal of Psychiatry, American Psychiatric Association; 162(2): 250-256.
10. Christodoulou G ., (2009): Maternity blues in Athens Greece: A study during the first 3 days after delivery. Journal of Affective Disorders, 99(1-3):107-15.

11. Douglas, C.J. (2008): Teaching supported therapy to psychiatric residents. American Journal of Psychiatry; 156(4): 445-452

12. Beck, C.T. (2002): Postpartum depression: a metasynthesis. Qualitative Health Research, 12, 453-472.

13. Laura, S., \& Abrams, G. (2011): Not just a middle class affliction: Crafting a social work research, Agenda on postpartum blues. Journal of Health and Social Work; 32:(11):290-296.

14. Dennis, C.L. \& Hodnett, E.D. (2009): Psychosocial and psychological interventions for treating postpartum blues (review). Wiley \& Sons: USA, pp. 426-433.

15. Kaveri, S.P. (2009): Post partum blues and depression. Palo Alto Medical Foundation. Available at: www.pamf.org/health/postpart um.

16. Klein, M., Rotenberg, N., Koren, D. (2009): Risk factors associated with the development of postpartum mood disorders. J. Affect. Disorder.; 88:9. 
17. Beck, C. (1999): Maternal depression and child behaviour problems: A meta-analysis. Journal of Advanced Nursing, 29(3), 623-629.

18. Salama, E.(2010): Associationbetween Corporal punishment in childhood and depressive symptoms among adolescents. 81.

19. Beck, C. T. (2008): State of the science on postpartum depression: What nurse researchers have contributedpart 2. MCN, American Journal of Maternal Child Nursing, 33(3), 151-156.

20. Lusskin, S.I, Pundiak, T.M and Habib, S.M. (2010): Perinatal depression: hiding in plain sight. Can. J. Psychiatry; 52:479.
21. Steiner,

M.

(2011):

Postpartum psychiatric disorders. Can. J. Psychiatry; 35:89.

22. Chen C.H., Tseng Y.F., Chou F.H. \& Wang S.Y. (2000): Effects of support group intervention in postnatally distressed women: a controlled study in Taiwan. Journal of Psychosomatic Research 49, 395-399.

23. Navaie-Waliser M., Martin S.L., Tessaro I., Campbell M.K. \&Cross A.W. (2000): Social support and psychological functioning among high-risk mothers: the impact of the baby love maternal outreach worker program. Public Health Nursing 17, 280-291 